Article

\title{
Sustaining Collaborative Effort in Work Teams: Exchange Ideology and Employee Social Loafing
}

\author{
Gukdo Byun ${ }^{1}$, Soojin Lee ${ }^{2, *}$, Steven J. Karau ${ }^{3}$ and Ye Dai ${ }^{3}$ \\ 1 School of Business, Chungbuk National University, Cheongju 28644, Korea; bgukdo@cbnu.ac.kr \\ 2 College of Business Administration, Chonnam National University, Gwangju 61186, Korea \\ 3 College of Business, Southern Illinois University, Carbondale, IL 62901, USA; \\ skarau@business.siu.edu (S.J.K.); ye.dai@business.siu.edu (Y.D.) \\ * Correspondence: soojinlee@jnu.ac.kr
}

Received: 15 July 2020; Accepted: 30 July 2020; Published: 3 August 2020

check for updates

\begin{abstract}
To sustain the effort of work team members as a collaborative resource over time, organizations need to avoid the social loafing of employees. Recognizing the importance of this relationship, we investigated both individual (i.e., exchange ideology) and situational factors (i.e., task visibility and professional respect) that influence employees' attitudes toward social exchange and team collaboration and thus their social loafing. Using survey responses of 223 employee-supervisor dyads in South Korean firms, hierarchical regression analyses demonstrated that employees with a low exchange ideology were unlikely to engage in social loafing. In addition, exchange ideology interacted with both task visibility and professional respect to influence social loafing. Specifically, task visibility was negatively associated with social loafing, and this effect was stronger when employees were low, rather than high, in exchange ideology. Moreover, professional respect was negatively associated with social loafing, and this effect was stronger among those low in exchange ideology. Thus, a low level of exchange ideology can reduce social loafing and can also enhance the potential for task visibility and professional respect to strengthen effort levels. Accordingly, this study suggested that individual characteristics, especially exchange ideology, are important in reducing social loafing and clearly stated what managerial guidelines can be implemented to practically reduce social loafing.
\end{abstract}

Keywords: social loafing; exchange ideology; task visibility; professional respect

\section{Introduction}

Business firms are striving to achieve and sustain high performance in today's highly competitive business environment. To accomplish this goal, these firms need to sustain the effort of work team members as a collaborative resource, an important input required for high firm performance, and avoid wasting the time and energy of employees. Although working in groups may increase efficiency and improve performance, this potential is seldom fully realized. Working in groups may make individuals feel "lost in the crowd" and provide an opportunity to "hide in the crowd" [1], often leading to reduced effort on collective tasks. How firms sustain the continuous effort and collaboration of employees to sustain the firms' competitive advantage remains an umbrella topic that has been intriguing researchers of organizational studies.

Among their endeavors, many scholars have attempted to identify under what conditions employees are likely to withhold their efforts, be less collaborative in team tasks, and thus engage in social loafing [2]. Social loafing refers to a tendency for individuals to reduce their effort when working collectively rather than individually (for reviews see Karau and Wilhau, Karau and Williams) [3,4]. 
In organizational settings, social loafing can be a prevalent factor that reduces the sustained efforts and collaboration of employees and organizational effectiveness and performance [2].

A wealth of research has documented social loafing in both laboratory and field settings, and has identified factors that can reduce or eliminate it [4]. Scholars have mainly focused on situational and contextual factors, such as contingent rewards and punishments [5], evaluation potential and task meaningfulness [4], and team member composition and perceptions of team interaction processes [2]. However, they have paid inadequate attention to the importance of personality and individual difference factors in influencing social loafing. Although researchers have investigated the effects of several individual difference factors, such as the need for cognition [6], achievement motivation [7], conscientiousness [8], protestant work ethic [9], and gender [10], this prior work has relied mainly on laboratory design methods and used student subjects, limiting the external validity of the findings. In one notable exception, Schippers [11] found that a high degree of both agreeableness and conscientiousness was negatively related to social loafing perceptions in student project teams. Yet, studies examining personality influences on social loafing in organizational work teams is lacking. To redress this gap, the current study examined the impact of exchange ideology on employee social loafing along with its potential interactive effects with task visibility and professional respect in work organizations from the perspective of social exchange theory [12].

The social exchange perspective suggests that most relationships, whether between multiple individuals or between individuals and organizations, are based on the exchange of tangible and intangible resources [13]. According to this understanding, the employment relationship is essentially an economic exchange relationship and most employees' motivation for job effort is based on economic considerations [14]. Thus, it is important to examine individuals' dispositional tendencies regarding their behavioral responses to exchange relationships. Some individuals are more sensitive to reciprocal exchange than others and thus have a high exchange ideology [15]. In a collaborative relationship, individuals with a high exchange ideology are especially attentive to and concerned with whether or not their efforts will lead to valued outcomes. They could thus be more susceptible to social loafing and exert less sustained efforts, given that the relationship between individual effort and individual outcomes is less obvious for group tasks than for individual tasks [4]. Therefore, in the current study, we examined the potential for exchange ideology to influence employee social loafing.

One key motivational reason for individuals to reduce their efforts on group tasks concerns their perception of identifiability [16]. From a social exchange perspective, individuals who are motivated economically tend to exert stronger effort when it is likely to lead to positive outcomes [17], and they are therefore likely to reduce social loafing when their individual contributions can be appropriately rewarded [16]. When an individual is assigned a task that is highly visible, it is easy for the supervisor to identify and reward the individual's contribution. Thus, with a high level of task visibility, individuals should be less motivated to engage in social loafing, particularly in finishing tasks assigned to them as individuals. Accordingly, this study examined employees' task visibility as a situational factor that may reduce social loafing.

Moreover, social exchange theory posits that individuals seek to reciprocate with others from whom they receive rewards or benefits [12]. Thus, when a leader respects employees for their professional abilities and skills, this might minimize the employees' tendency to slack off on group tasks to the extent that they feel the need to reciprocate this recognition. Based on this reasoning, this study investigated supervisors' professional respect as an important situational factor that may reduce employees' social loafing. Additionally, exchange ideology is unlikely to operate in isolation and its impact on social loafing can be influenced by task visibility and leaders' professional respect as two situational or contextual variables. Accordingly, we tested how task visibility and professional respect each interact with exchange ideology in influencing employees' social loafing.

This study contributes to the extant literature in three ways. First, it demonstrates the effects of both dispositional and situational factors on social loafing. Second, in contrast to prior social loafing studies exploring individual differences that have relied heavily on laboratory data collected 
from student subjects, this study examines personality and situational influences on social loafing collected from employee-supervisor dyads in actual organizations. Third, this study applies social exchange theory, which has been neglected in prior social loafing research, to derive hypotheses about the previously unexplored effects of individual differences in exchange ideology, both alone and in interaction with situational factors, on social loafing. Practically, this study provides implications for improving the sustainability of employees' efforts and collaboration and thus the sustainability of team, group, and organizational success.

\section{Hypotheses Development}

\subsection{Exchange Ideology and Social Loafing}

The concept of exchange ideology refers to the strength of individuals' beliefs about how well the organization treats them and provides them with tangible benefits in relation to their efforts toward achieving organizational goals [18]. This concept has long been considered as a dispositional orientation that is stable [15]. Eisenberger et al. [15] demonstrated that individuals with different concerns and considerations regarding the relevance and importance of the norm of reciprocity can respond differently, even within similar social exchange relationships. Specifically, employees high in exchange ideology will work harder when they believe they will be treated well and will receive favorable outcomes equal to or exceeding their fair share, whereas employees low in exchange ideology tend to display more stable levels of effort regardless of the outcomes they expect to receive [19]. Employees with a high exchange ideology are highly sensitive to rewards and outcomes but attach lesser value to long-term relationships [20]. Additionally, they show more interest in giving and receiving direct and immediate benefits from social transactions [21] and thus closely monitor what they can receive in the short term [22]. Group tasks typically produce less direct rewards or outcomes for employees than do individual tasks. Therefore, employees with high exchange ideology should attach less value to group tasks, be more concerned with the lack of direct reward, and readily engage in social loafing. However, employees with low exchange ideology, who are less sensitive to exchange relationships, should show lower levels of social loafing and display more stable levels of effort even when short-term tangible rewards are less salient.

This reasoning is further reinforced by the collective effort model (CEM; [4]) that combines elements of the expectancy theory of motivation with social identity and group-level social comparison perspectives. Expectancy theory (e.g., Vroom) [23] suggests that individuals will only work hard on a collective task when they expect their efforts to be highly instrumental in producing outcomes that they personally value. However, group tasks create more barriers to such perceptions than do individual tasks. Social identity [24] and group-level social comparison theories [25] suggest that group tasks are more likely to be motivating to individuals when the associated outcomes contribute to maintaining a favorable self-view in relation to the accomplishment of groups that an individual belongs to or strongly identifies with. However, the model also emphasizes that there are individual differences in the perception regarding group tasks and the degree to which collective outcomes are valued [26]. Individuals low in exchange ideology place more value on social and intangible outcomes (e.g., respect, appreciation, or the nature of ongoing relationships), whereas those high in exchange ideology place more value on tangible, short-term outcomes (e.g., the distribution of rewards and the likelihood of receiving individual benefits; [20]). Therefore, high levels of exchange ideology should exacerbate social loafing by highlighting the reduced contingency between effort and short-term individual outcomes that is typical in most group tasks. In contrast, low levels of exchange ideology should reduce social loafing because it lessens the relative emphasis on short-term favorable rewards and treatment from the organization. Therefore, we propose:

Hypothesis 1. Employees' exchange ideology is positively related to social loafing. 


\subsection{Task Visibility and Social Loafing}

Task visibility refers to the degree to which an individual's effort on a task is readily observable and can be objectively assessed by his or her supervisor [16]. Task visibility can be influenced by the level of the supervisor's monitoring and evaluation capability [17]. Social exchange theory [12] suggests that, when individuals believe that their efforts are visible to their supervisor, they become motivated to exert effort in their job because increased identifiability helps them achieve their desired outcomes. Namely, people who are motivated economically tend to exert effort when they know they will be rewarded appropriately [17]. On the contrary, with low task visibility, employees may believe that they will be assessed primarily based on shared group outcomes and that additional effort will not bring about reward proportional to the effort [16]. Accordingly, a number of laboratory studies have shown that social loafing can be reduced or eliminated by making individuals' inputs identifiable [27] or easy to evaluate [28]. Some field studies have also found that perceptions of task visibility or accountability are associated with reduced levels of perceived loafing (e.g., George, Liden et al.) [16,29].

The effect of task visibility on social loafing can also be explained by the CEM. Namely, the CEM suggests that individuals work harder when their outputs are visible or can be easily evaluated because this condition strengthens the contingencies between individual effort and the valued outcome of praise, reward, or recognition [4]. Thus, based on converging evidence from prior theories and research, we propose:

\section{Hypothesis 2. Task visibility is negatively related to social loafing.}

\subsection{Professional Respect and Social Loafing}

People are entitled to a certain respect by virtue of being human [30]. Professional respect refers to admiration and esteem for the individual's expert abilities or skills [31]. Although collective tasks typically reduce the likelihood that individual efforts will be directly rewarded in a favorable manner, professional respect and acknowledgement by one's supervisor may counterbalance this and reduce social loafing by boosting employees' perceptions of reciprocity obtained from social exchange relationships, leading employees to feel that even their less directly rewarded efforts are nevertheless appreciated by their supervisors [12].

Liden and Maslyn [31] treated respect as a subdimension, along with affect, loyalty, and contribution, of the leader-member exchange relationship (LMX). In collective work, professional respect for employees may affect the magnitude of one's psychological motivation for group work. Indeed, Murphy et al. [32] found that low quality leader-member exchange is associated with higher levels of social loafing, lending support for a similar role that could be played by professional respect. Among the four subdimensions of LMX, whereas affect, loyalty, and contribution depend on direct dyadic exchanges between leaders and followers, professional respect instead reflects general professional reputation because it is possible to have a perception of this even when regular, direct interactions are limited [31]. Hence, the current study chose to focus on professional respect among the LMX dimensions because this concept incorporates concerns about long-term intangible social and relational outcomes rather than immediate tangible rewards, which individuals with low exchange ideology may care about.

From a social exchange perspective, when supervisors and organizations show professional respect for their employees' abilities and skills, the employees may be motivated to reciprocate this respect proportionally. They may seek to exert more effort and make valuable contributions by using their professional skills to accomplish organizational objectives. Similarly, applying the logic of the CEM, because professional respect may make individuals feel more appreciated or acknowledged, they may attach greater value to the outcomes of group tasks. Professional respect might also boost intrinsic motivation and instrumentality perceptions by fostering beliefs that one's work is meaningful and contributes to the organization. Indeed, prior research has shown that social loafing is more likely to occur when individuals see their contributions as unimportant or redundant with those of other 
group members (e.g., Harkins and Petty) [33]. Therefore, based on social exchange theory, the CEM, and relevant prior LMX research, we propose:

Hypothesis 3. Professional respect is negatively related to social loafing.

\subsection{Interaction Effects}

Individual difference factors (e.g., exchange ideology) and contextual factors (e.g., task visibility and professional respect) could also interact to predict employees' social loafing. Specifically, whereas individuals with low levels of exchange ideology might be fairly responsive to factors that reduce social loafing through the potential for social approval and acknowledgement for their professional skills, individuals with high levels of exchange ideology might be comparatively unmoved by such variables and continue to engage in social loafing unless tangible, short-term rewards are directly linked to their efforts. Consistent with this reasoning, employees low in exchange ideology respond to open exchanges within the organization that may have a subjectively positive interpretation, but employees high in exchange ideology expect more direct, symmetric, and economic-oriented exchanges [19]. This study thus posits that task visibility and professional respect are more likely to reduce social loafing among individuals low in exchange ideology. In contrast, a high level of exchange ideology may neutralize the positive effects of these situational factors on social loafing. This is because respect and visibility do not ensure direct, tangible rewards and outcomes in and of themselves (which are more motivating to high exchange ideology employees) but are merely associated with the positive social perceptions of others. Employees low in exchange ideology place greater emphasis on both long-term tangible outcomes and on social and interpersonal outcomes $[20,21]$. Therefore, the capacity of professional respect and task visibility to reduce social loafing should be stronger for employees who are low, rather than high, in exchange ideology.

Regarding task visibility, Huseman et al. [22] suggested that employees low in exchange ideology are more tolerant of under-reward by their organizations and supervisors, whereas employees high in exchange ideology, focusing more on immediate rewards, are less tolerant of under-reward. Collective tasks increase the likelihood of such under-reward in that they often reward based on shared group outcomes rather than on individual contributions. Coyle-Shapiro and Neuman [19] also suggested that those high in exchange ideology are more sensitive to the economic gains that they receive and are more likely to feel that the organization owes them economic rewards compared with employees low in exchange ideology. Thus, when task visibility is high, employees low in exchange ideology should increase their effort on the group task because they feel that their supervisor's observation and assessment of their performance will affect the social relationship in the long term. Even though supervisors' perception of their work attitudes and performance may not provide immediate, tangible resources, employees low in exchange ideology may still try to foster supervisors' good impressions about them [22].

By contrast, employees high in exchange ideology may be less sensitive to task visibility because they have more interest in immediate, tangible rewards than in the more distant threat of social evaluation. That is, high exchange ideology may attenuate the positive effect of task visibility on decreasing social loafing. Indeed, Chiaburu and Baker [34] found a similar effect of exchange ideology on the relationship between the propensity to trust and taking charge. Specifically, they found that the relationship between the propensity to trust and taking charge was stronger among employees who were low, rather than high, in exchange ideology. Similarly, high exchange ideology could also attenuate the usually positive effects of task visibility on willingness to exert effort on a group task. Therefore, we propose:

Hypothesis 4. The negative relationship between task visibility and social loafing is moderated by exchange ideology such that this relationship is stronger when exchange ideology is low than when it is high. 
Similarly, professional respect should have less of a positive effect on effort levels for those high in exchange ideology because they are more economically oriented and focus on immediate, tangible aspects of transactions. Hence, professional respect should be more helpful in increasing the effort of those low in exchange ideology (who value long-term interpersonal outcomes) than those high in exchange ideology (who place greater emphasis on more immediate, tangible outcomes). In other words, high exchange ideology may attenuate the positive effects of professional respect on decreased levels of social loafing. Thus, we expected the following:

Hypothesis 5. The negative relationship between professional respect and social loafing is moderated by exchange ideology such that this relationship is stronger when exchange ideology is low than when it is high.

Figure 1 represents our research model.

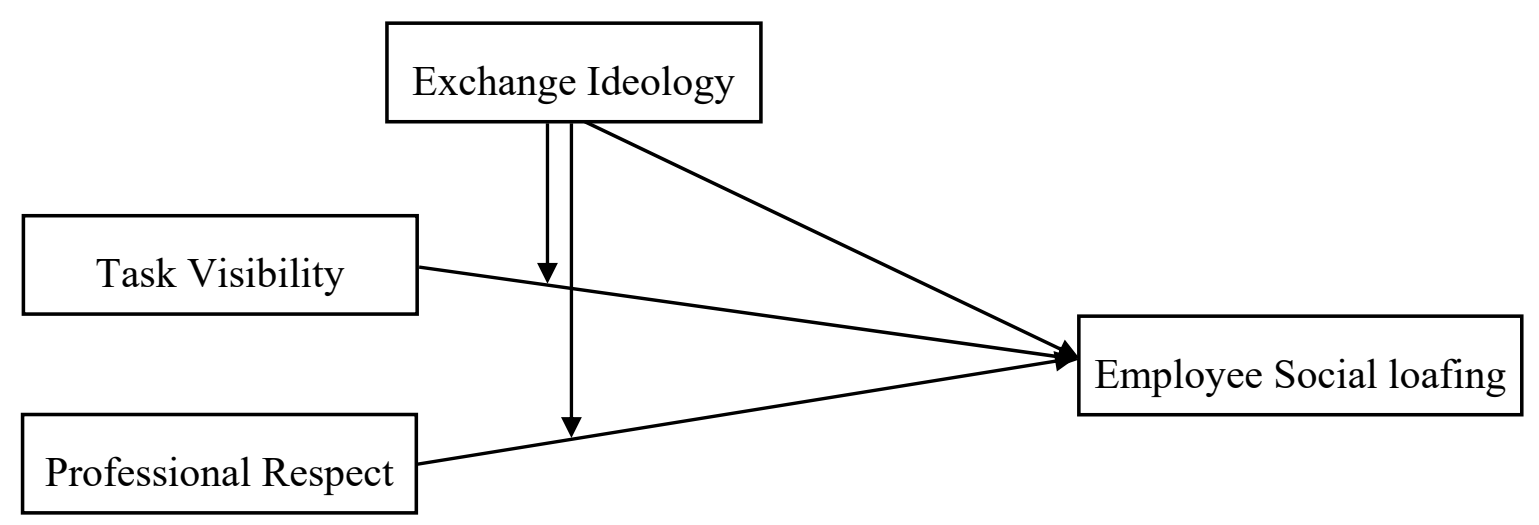

Figure 1. Hypothesized model.

\section{Method}

\section{Participants and Procedures}

Data were collected from six major companies in South Korea as a part of a large leadership project. Most respondents were full-time employees in international electronics companies, international automobile companies, and nationwide telecom companies. Within each company, samples were selected randomly by HR managers, and separate questionnaires for each employee and for his or her immediate supervisor were distributed. All participants were informed that this was an anonymous and confidential survey only for academic purposes. All scale items were translated into Korean and back-translated by two bilingual (English-Korean) speakers to ensure semantic equivalence [35]. Three hundred and thirty-five pairs of surveys were distributed. Two hundred and sixty-two subordinate surveys and 244 supervisor surveys were returned, resulting in response rates of $78.2 \%$ for subordinates and $72.8 \%$ for supervisors. Excluding unmatched responses and missing data resulted in a final sample of 223 matched pairs of supervisors and subordinates. Of the subordinates, $45.3 \%$ were male and their average age was 34.13 years $(S D=5.51)$. Of the supervisors, $55 \%$ were male and their average age was 41.95 years $(\mathrm{SD}=6.17)$.

\section{Measures}

All items were measured on a seven-point Likert scale (ranging from 1 = strongly disagree to $7=$ strongly agree). Subordinates reported their perceptions of exchange ideology and task visibility. Supervisors rated their respect for subordinates and their subordinates' levels of social loafing.

Exchange ideology. Exchange ideology was measured using eight items from Eisenberger et al. [15]. A sample item reads "An employee who is treated badly by a company should work less hard." 
Task visibility. Employees reported their perceptions of task visibility using six items from George [16]. A sample item reads "It is generally hard for my supervisor to figure out how hard I am working."

Professional respect. Professional respect for employees was measured using three items from Liden and Maslyn [31]. A sample item reads "I respect this employee's knowledge and competence on the job."

Social loafing. Employees' social loafing was rated by their leader using nine items from George [16]. A sample item stated "(The employee) puts forth less effort on the job when other employees are around to do the work."

Control variables. In our regression analyses, we included control variables for subordinates' age, gender, organizational tenure, and tenure with their direct supervisors, as well as for supervisors' age and gender. These variables have been statistically controlled in several prior studies on social loafing [32] and exchange ideology [20]. Subordinates' job tenure and tenure with their supervisors were measured in months.

\section{Results}

The means, standard deviations, reliabilities, and correlations among the key variables are reported in Table 1. All measures had alpha levels equal to or higher than 0.84, suggesting good internal consistency, and their correlations were as expected. Additionally, employee age was not significantly correlated with social loafing. In terms of gender, men show more social loafing than women, and organizational tenure was negatively correlated with social loafing.

\section{Test of Hypotheses}

To test main and interaction effects on social loafing, we used hierarchical regression analyses with a relevant second-degree term entered in subsequent steps. To alleviate potential multicollinearity problems, exchange ideology, task visibility, and professional respect were mean-centered before we created the second-degree term [36]. Table 2 presents the results of the hierarchical regression analyses. Hypothesis 1 predicts that exchange ideology is positively related to social loafing. As shown by Model 2A, the coefficient for exchange ideology was significant and positive $(\beta=0.24, p \leq 0.001)$. Therefore, Hypothesis 1 was supported. Hypotheses 2 and 3 predict that task visibility and professional respect are both negatively associated with social loafing. In Model 2B, the coefficient for task visibility was significant and negative $(\beta=-0.13, p \leq 0.05)$, and the coefficient for professional respect was also significant and negative $(\beta=-0.43, p \leq 0.001)$. Therefore, Hypotheses 2 and 3 were supported.

Hypothesis 4 and Hypothesis 5 predict that exchange ideology interacts with task visibility and professional respect, respectively, to influence levels of social loafing. Regarding Hypothesis 4 , in Model 3, the interaction term for exchange ideology and task visibility was significant $(\beta=0.13, p \leq 0.05)$. Regarding Hypothesis 5 , Model 3 shows that the interaction term for exchange ideology and professional respect was significant $(\beta=0.15, p \leq 0.05)$. Finally, both the interaction terms in Model 3 accounted for additional variance $\left(\Delta R^{2}=0.04\right)$ well above what was explained by variables included in previous steps $(\Delta F=5.46, p \leq 0.01)$.

To further examine the interaction effects, we plotted the results using the procedure of Aiken and West [36]. As shown in Figure 2, consistent with Hypothesis 4, there is a negative relationship between task visibility and social loafing when exchange ideology is low. In addition, we further conducted a simple slopes test. The findings showed that the relationship between task visibility and social loafing is not significant when exchange ideology is high $(+1 \mathrm{SD})(\beta=0.13, t=1.45, \mathrm{~ns})$. However, when exchange ideology is low $(-1 \mathrm{SD})$, the relationship is significant and negative $(\beta=-0.20, t=-2.38$, $p \leq 0.05)$. Namely, as expected, task visibility has a stronger effect on reducing social loafing among individuals who are low, rather than high, in exchange ideology. Therefore, the results supported Hypothesis 4. 
Table 1. Means, standard deviations, and correlations.

\begin{tabular}{|c|c|c|c|c|c|c|c|c|c|c|c|c|c|}
\hline & Variable & Mean & SD & 1 & 2 & 3 & 4 & 5 & 6 & 7 & 8 & 9 & 10 \\
\hline 1. & Employee age $^{\mathrm{a}}$ & 34.13 & 5.51 & & & & & & & & & & \\
\hline 2. & Employee gender ${ }^{a}$ & 1.55 & 0.50 & 0.02 & & & & & & & & & \\
\hline 3. & Employee organizational tenure ${ }^{a}$ & 6.30 & 4.84 & $0.64^{* * *}$ & 0.09 & & & & & & & & \\
\hline 4. & Employee tenure with their leader ${ }^{a}$ & 2.03 & 2.21 & $0.26^{* * *}$ & 0.06 & $0.35^{* * *}$ & & & & & & & \\
\hline 5. & Leader age ${ }^{b}$ & 41.95 & 6.17 & $0.25^{* * *}$ & -0.08 & $0.33 * * *$ & 0.02 & & & & & & \\
\hline 6. & Leader gender ${ }^{b}$ & 1.45 & 0.50 & $0.15 *$ & $0.58^{* * *}$ & $0.26^{* * *}$ & 0.11 & $-0.24 * * *$ & & & & & \\
\hline 7. & Exchange ideology ${ }^{a}$ & 3.70 & 1.15 & -0.06 & -0.02 & 0.03 & -0.03 & -0.03 & -0.02 & $(0.88)$ & & & \\
\hline 8. & Task visibility ${ }^{a}$ & 4.96 & 0.96 & -0.03 & $0.19 * *$ & 0.00 & -0.05 & -0.08 & $0.17^{* *}$ & $-0.31^{* * *}$ & $(0.84)$ & & \\
\hline 9. & Professional respect for employee ${ }^{b}$ & 5.25 & 1.21 & $0.16^{*}$ & 0.10 & $0.15^{*}$ & 0.03 & -0.02 & $0.14^{*}$ & $-0.30 * * *$ & $0.19 * *$ & $(0.95)$ & \\
\hline 10. & Employee social loafing ${ }^{b}$ & 2.19 & 1.07 & -0.06 & $-0.19 * *$ & $-0.15 *$ & -0.06 & -0.07 & $-0.23^{* * *}$ & $0.24^{* * *}$ & $-0.16^{*}$ & $-0.45^{* * *}$ & $(0.92)$ \\
\hline
\end{tabular}

Note. $\mathrm{N}=223$. Reliabilities are on the diagonal in parentheses. ${ }^{\text {a }}$ These variables were measured from employees. ${ }^{\mathrm{b}}$ These variables were measured from leaders. ${ }^{*} p \leq 0.05 ;{ }^{* *} p \leq 0.01$; ${ }^{* * *} p \leq 0.001$. 
Table 2. Results of hierarchical regression analysis for hypotheses.

\begin{tabular}{|c|c|c|c|c|c|}
\hline & \multicolumn{5}{|c|}{ Employee Social Loafing $^{\text {a }}$} \\
\hline & Model 1 & Model 2A & Model 2B & Model 2C & Model 3 \\
\hline \multicolumn{6}{|l|}{ Step 1: control variables ${ }^{b}$} \\
\hline Employee age & 0.06 & 0.10 & 0.06 & 0.12 & 0.12 \\
\hline Employee gender & -0.08 & -0.08 & -0.07 & -0.06 & -0.05 \\
\hline Employee organizational tenure & -0.10 & -0.14 & -0.09 & -0.06 & -0.07 \\
\hline Employee tenure with their leader & -0.02 & 0.01 & -0.03 & -0.03 & -0.04 \\
\hline Leader age & -0.10 & -0.09 & -0.11 & -0.13 & $-0.16^{*}$ \\
\hline Leader gender & $-0.18 *$ & $-0.17 *$ & $-0.17 *$ & -0.15 & -0.14 \\
\hline \multicolumn{6}{|l|}{ Step 2: Main effects } \\
\hline Exchange ideology (EXID) & & $0.24^{* * *}$ & & & 0.06 \\
\hline Task visibility (TV) & & & $-0.13^{*}$ & & 0.02 \\
\hline Professional respect (PR) & & & & $-0.43^{* * *}$ & $-0.42^{* * *}$ \\
\hline \multicolumn{6}{|l|}{ Step 3: interaction effects } \\
\hline$\overline{\text { EXID }^{c} \times T^{d}}$ & & & & & $0.13 *$ \\
\hline $\mathrm{EXID}^{\mathrm{c}} \times \mathrm{PR}^{\mathrm{e}}$ & & & & & $0.15 *$ \\
\hline Overall F & $2.94^{* *}$ & $4.81^{* * *}$ & $3.15^{* *}$ & $10.45^{* * *}$ & $8.42 * * *$ \\
\hline $\mathrm{R}^{2}$ & 0.08 & 0.13 & 0.09 & 0.25 & 0.30 \\
\hline Change in $\mathrm{F}$ & & $14.39^{* * *}$ & $3.74 *$ & $51.38^{* * *}$ & $5.46^{* *}$ \\
\hline Change in $\mathrm{R}^{2}$ & & 0.06 & 0.02 & 0.18 & 0.04 \\
\hline
\end{tabular}

Note. $\mathrm{N}=223$. ${ }^{\mathrm{a}}$ Entries are standardized regression coefficients. ${ }^{\mathrm{b}}$ Variables are standardized. ${ }^{\mathrm{c}} \mathrm{EXID}=$ exchange ideology, ${ }^{\mathrm{d}} \mathrm{TV}=$ task visibility, ${ }^{\mathrm{e}} \mathrm{PR}=$ professional respect. ${ }^{*} p \leq 0.05 ;{ }^{* *} p \leq 0.01 ;{ }^{* * *} p \leq 0.001$.

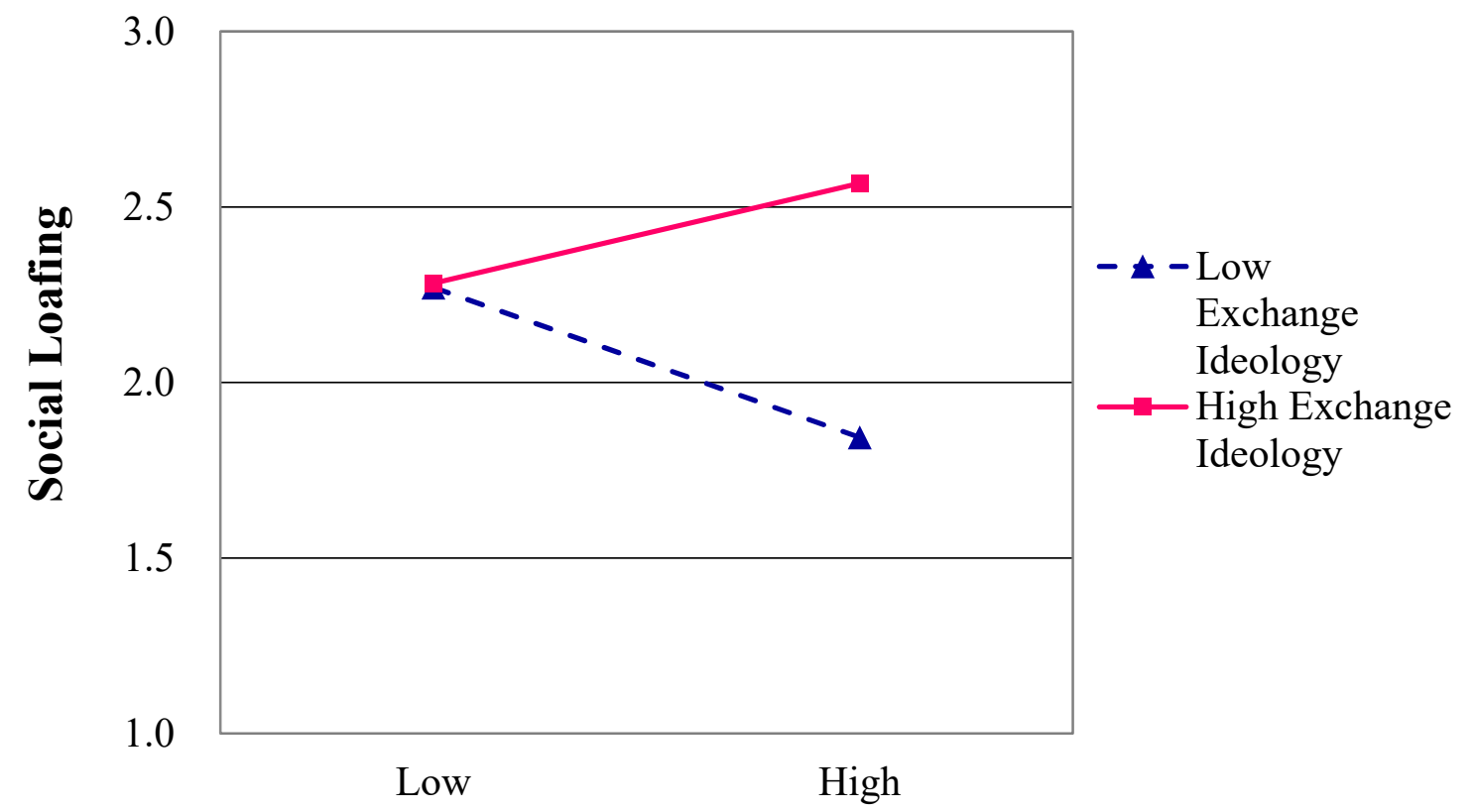

Task Visibility

Figure 2. Interaction effects of task visibility and exchange ideology on social loafing.

Also, as shown in Figure 3, the negative relationship between professional respect and social loafing is also stronger when exchange ideology is low, rather than high. Simple slopes tests confirmed that professional respect has a stronger negative effect on social loafing when exchange ideology is low $(\beta=-0.59, t=-6.05, p \leq 0.001)$ than when it is was high $(\beta=-0.29, t=-4.01, p \leq 0.001)$. Thus, Hypothesis 5 was supported. 


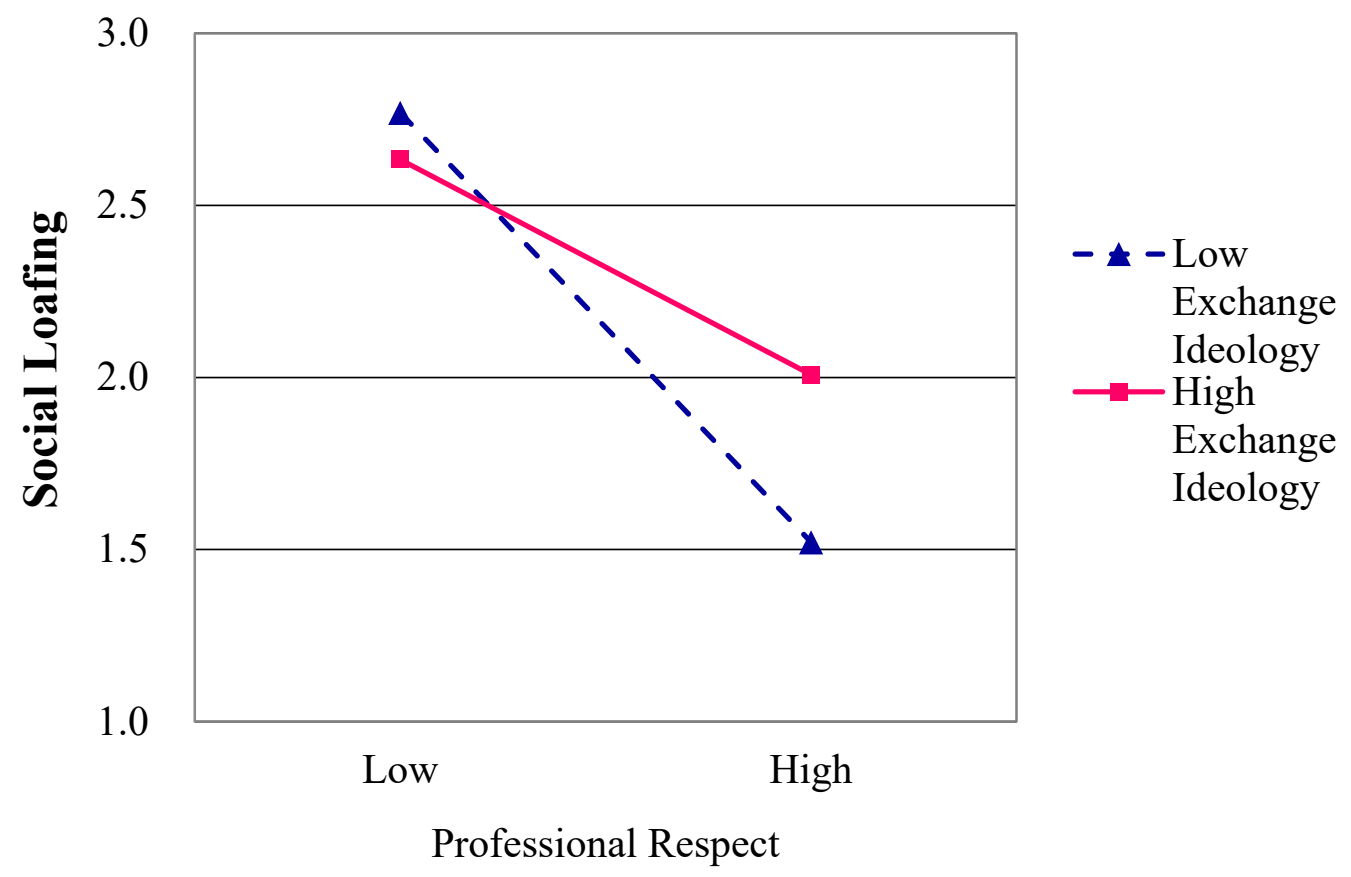

Figure 3. Interaction effects of professional respect and exchange ideology on social loafing.

\section{Discussions}

This study demonstrates that low levels of exchange ideology are associated with a significant reduction in employees' tendency for social loafing and also enhance the impact of supervisory and contextual factors that might reduce or eliminate social loafing. Specifically, our results showed that individuals low in exchange ideology were less prone to reducing their efforts in group tasks. In addition, professional respect from one's supervisor and task visibility both significantly reduced social loafing. Moreover, both factors interacted with exchange ideology. Namely, the tendency for professional respect to decrease employees' social loafing was stronger among those low, rather than high, in exchange ideology. Similarly, whereas task visibility was associated with reduced levels of social loafing for those low in exchange ideology, it was actually associated with slightly increased levels of social loafing for those high in exchange ideology.

Our findings contribute to the literature on group motivation in several ways. First, given that the extant literature on social loafing has focused on situational factors, our results highlight the importance of personality factors when designing and deploying strategies for getting the best effort and performance out of employees. In the case of exchange ideology, our findings suggest that individuals paying attention to immediate, tangible outcomes are more likely to slack off on group tasks and less likely to respond to social evaluation approaches that motivate individuals paying attention to longer term, interpersonal outcomes. Thus, this study provides further evidence for the importance of individual differences in motivation to work hard on collective tasks. It also represents a rare empirical demonstration of the influence of personality factors on social loafing within intact organizations.

Our results for the outcome of social loafing are in line with recent empirical studies $[20,21,34,37]$ that provided evidence for a similar moderating effect of exchange ideology on other aspects of organizational behavior. For example, Redman and Snape [21] found that the positive relationship between union support and union commitment and citizenship behavior was stronger for employees low in exchange ideology than for those high in exchange ideology. Similarly, our results demonstrate that exchange ideology exacerbates social loafing and reduces or eliminates the potential for task visibility and professional respect to strengthen effort levels. These findings suggest that individuals high in exchange ideology are more likely to be self-focused and calculative, providing a new perspective 
on exchange ideology in employment relationships. Future research can identify additional factors that may interact with exchange ideology to influence effort on collective tasks.

Second, our findings suggest that it is necessary to include supervisory factors to explain social loafing. Although many studies have examined the impact of leaders on a range of individual and group outcomes, there has been little research on leader influences in social loafing literature. Instead, the literature has largely focused on situational factors. We found that the professional respect paid by leaders to their employees decreased overall levels of social loafing and also interacted with exchange ideology such that professional respect only reduced social loafing among employees low in exchange ideology. In addition, the results of this study offer findings regarding the impact of task visibility on social loafing. Consistent with prior studies $[16,17,29]$, we found that the degree of task visibility was significantly associated with the level of social loafing, perhaps by making performance-to-outcome perceptions (i.e., instrumentalities) more obvious (consistent with the expectancy theory of motivation; [23]). Yet our findings also go beyond prior task visibility research by showing that the effects of task visibility on reduced social loafing are stronger for individuals who are low, rather than high, in exchange ideology. Our findings thus present evidence for how individual differences and situational contextual variables can have both main and interactive effects on individual motivation.

Third, our results provide further evidence for the value of both social exchange theory and the CEM in understanding employee motivation to work hard on collective tasks. Namely, our research builds on prior research on exchange relationships [17] and leader-member exchange [21,32] to reinforce the general value of social exchange theory to social loafing and to further apply that understanding to the specific operation of exchange ideology on motivation in collective tasks, both alone and in combination with supervisory and situational factors. Regarding the CEM, our results provide additional evidence that the model is not only useful as an integrative tool for explaining prior research (as in the meta-analysis of Karau and Williams) [4], but can also be used to derive and test hypotheses about previously unexplored relationships (for additional examples, see Karau and Williams) [26].

Finally, this study explored the factors that affect individuals' tendencies to loaf in an Eastern cultural context-specifically, in South Korea. Many researchers have suggested that Western culture is individualistically oriented and has relatively low power distance, whereas Eastern culture has a preference for collectivism and high power distance [38]. Also, a few studies have suggested that individuals from cultures of high individualism and low power distance are more likely to engage in social loafing than individuals from cultures of high collectivism and high power distance [39]. However, Karau and Williams [26] pointed out that most studies on social loafing have been conducted in Western cultures. The current study investigated the potential for exchange ideology as an individual difference and task visibility and professional respect as contextual factors to reduce or eliminate social loafing in Eastern culture. Thus, it broadens, to some extent, the potential cultural generalizability of certain mechanisms that may lead to social loafing. Future researcher can cross-validate our findings in Western cultures.

\subsection{Practical Implications}

Our study also has implications for practitioners in their effort to boost the sustained efforts and collaboration of employees and thus the sustainability of firm performance. The most direct applications concern exchange ideology. First, our findings suggest that leaders may have difficulty in motivating employees high in exchange ideology when using strategies that are not based on tangible short-term rewards. These individuals, who are more interested in reward and compensation, may not be motivated to participate in collective tasks without any personal benefit and may also be resistant to evaluation and social strategies that other employees respond to. By contrast, our study also suggests that employees low in exchange ideology may display fewer social loafing behaviors in general and may also be less likely to decrease their efforts on collective tasks when they are held in high regard or when their efforts are more readily visible to the leader. Thus, leaders need to consider individual 
differences, especially exchange ideology, when seeking to maximize employee effort and decrease social loafing on collective tasks. Further, though conceptualized as a disposition, exchange ideology could still be influenced by situational factors such as team collectivism culture and social integration. Therefore, supervisors can implement training practices to increase team members' awareness of group benefits and thus reduce their exchange ideology.

Our findings also lend insight into how leaders might manage teams based on members' levels of exchange ideology. Regarding task visibility, for example, a team can use project management software to plan, track, and update their project, create project communication plans, and organize kick-off meetings and weekly team meetings to boost the task visibility of team members. These approaches, making individuals more visible, identifiable, or accountable, may have a greater positive impact on low exchange ideology members, but they may have minimal or no impact among those high in exchange ideology. Perhaps visibility would be more impactful among individuals high in exchange ideology when it is clearly linked to shorter term outcomes.

This study also highlights the value of professional respect as a tool that leaders can use in motivating employees. Scholars have emphasized the importance of recognition for subordinates [40] and even suggested that recognition and compliments can make "whales dance" [41]. Professional respect is one form of recognition [30] and can manifest itself in compliments and appreciation for subordinates. Thus, our study provides empirical evidence for the positive effect of recognition on employee motivation. Furthermore, our findings show that the positive effects of professional respect on motivation are diminished among individuals high in exchange ideology.

\subsection{Limitations and Future Directions}

Although our study makes several contributions, it also has some limitations that might be addressed in future research. First, we used a cross-sectional design and thus may limit the conclusions with regard to the causal order of variables. Future studies could use experimental, quasi-experimental, or longitudinal approaches to provide more support for the suggested causal relationships. Second, although our data set included measures taken from both employees and supervisors, the data for professional respect for employees and social loafing came from the same source (i.e., supervisor report) and thus may suffer from common method bias. To check for common method bias, we conducted Harman's single factor test [42]. All variables were loaded onto a single factor in an unrotated factor analysis in SPSS. A newly introduced common latent factor explained $33.47 \%$ of the total variance, well below the threshold of $50 \%$. The result indicates that common method bias is not a serious concern in our data. Furthermore, the use of supervisor ratings can help to avoid potential social desirability biases in self-ratings and halo biases in peer ratings. Indeed, meta-analytic findings have shown that individuals are often either unable to recognize their own social loafing or unwilling to admit it [4] and that peer reports of job performance often show substantial halo bias [43].

Finally, we focused on testing the existence of the predicted relationships rather than measuring specific processes through which these outcomes have occurred. A promising future direction would be to include additional measures of process variables as well as to measure additional potential moderators. For example, in the relationship between individual and situational characteristics and social loafing, the psychological mechanism of individuals, especially decreased organizational commitment and low levels of job engagement, may serve as a mediator between the two. Moreover, it will be meaningful to review team-member exchange (TMX) or group cohesiveness as additional moderators in future research. We are hopeful that our findings might stimulate further research on the dynamics of group motivation.

\section{Conclusions}

Firm sustainability is an area of research that has long been intriguing researchers of macro-organizational behaviors. Different from this mainstream approach, our study examines factors, such as exchange ideology and task visibility, that influence the sustainability of firm performance from 
a micro perspective. We hope that our study will contribute to firm sustainability studies and motivate future researchers who, adopting this perspective, will be able to identify more micro organizational factors that influence firm sustainability.

Author Contributions: Conceptualization, G.B., S.J.K., and S.L.; Data curation, G.B. and S.L.; Formal analysis, G.B.; Funding acquisition, G.B.; Investigation, S.L.; Methodology, G.B. and S.L.; Project administration, S.J.K. and S.L.; Writing—original draft, G.B. and Y.D.; Writing—review and editing, S.L., S.J.K., and Y.D. All authors have read and agreed to the published version of the manuscript.

Funding: This work was supported by the Ministry of Education of the Republic of Korea and the National Research Foundation of Korea (NFR-2019S1A5A8033908).

Conflicts of Interest: The authors declare no conflict of interest.

\section{References}

1. Davis, J.H. Group Performance; Addison-Wesley: Boston, MA, USA, 1969.

2. Price, K.H.; Harrison, D.A.; Gavin, J.H. Withholding inputs in team contexts: Member composition, interaction processes, evaluation structure, and social loafing. J. Appl. Psychol. 2006, 91, 1375-1384. [CrossRef] [PubMed]

3. Karau, S.J.; Wilhau, A.J. Social loafing and motivation gains in groups: An integrative review. In Individual Motivation within Groups: Social Loafing and Motivation Gains in Work, Academic, and Sports Teams; Karau, S.J., Ed.; Academic Press: San Diego, CA, USA, 2020; pp. 3-51.

4. Karau, S.J.; Williams, K.D. Social loafing: A meta-analytic review and theoretical integration. J. Pers. Soc. Psychol. 1993, 65, 681-706. [CrossRef]

5. George, J.M. Asymmetrical effects of rewards and punishments: The case of social loafing. J. Occup. Organ. Psychol. 1995, 68, 327-338. [CrossRef]

6. Smith, B.N.; Kerr, N.A.; Markus, M.J.; Stasson, M.F. Individual differences in social loafing: Need for cognition as a motivator in collective performance. Group Dyn. Theory, Res. Pr. 2001, 5, 150-158. [CrossRef]

7. Hart, J.W.; Karau, S.J.; Stasson, M.F.; Kerr, N.A. Achievement Motivation, Expected Coworker Performance, and Collective Task Motivation: Working Hard or Hardly Working? J. Appl. Soc. Psychol. 2004, 34, 984-1000. [CrossRef]

8. Hoon, H.; Tan, H.H. Organizational Citizenship Behavior and Social Loafing: The Role of Personality, Motives, and Contextual Factors. J. Psychol. 2008, 142, 89-108. [CrossRef] [PubMed]

9. Smrt, D.L.; Karau, S.J. Protestant work ethic moderates social loafing. Group Dyn. Theory, Res. Pr. 2011, 15, 267-274. [CrossRef]

10. Kugihara, N. Gender and Social Loafing in Japan. J. Soc. Psychol. 1999, 139, 516-526. [CrossRef]

11. Schippers, M. Social Loafing Tendencies and Team Performance: The Compensating Effect of Agreeableness and Conscientiousness. Acad. Manag. Learn. Educ. 2014, 13, 62-81. [CrossRef]

12. Blau, P.M. Exchange and Power in Social Life; Wiley: New York, NY, USA, 1964.

13. Emerson, R.M. Social Exchange Theory. Annu. Rev. Sociol. 1976, 2, 335-362. [CrossRef]

14. Brief, A.P.; Aldag, R.J. The economic functions of work. In Research in Personnel and Human Resources Management; Rowland, K., Ferris, G.R., Eds.; JAI Press: Stamford, CT, USA, 1989.

15. Eisenberger, R.; Huntington, R.; Hutchison, S.; Sowa, D. Perceived organizational support. J. Appl. Psychol. 1986, 71, 500-507. [CrossRef]

16. George, J.M. Extrinsic and Intrinsic Origins of Perceived Social Loafing in Organizations. Acad. Manag. J. 1992, 35, 191-202. [CrossRef]

17. Jones, G.R. Task Visibility, Free Riding, and Shirking: Explaining the Effect of Structure and Technology on Employee Behavior. Acad. Manag. Rev. 1984, 9, 684-695. [CrossRef]

18. Andrews, M.C.; Witt, L.; Kacmar, K.M. The interactive effects of organizational politics and exchange ideology on manager ratings of retention. J. Vocat. Behav. 2003, 62, 357-369. [CrossRef]

19. Coyle-Shapiro, J.A.-M.; Neuman, J.H. The psychological contract and individual differences: The role of exchange and creditor ideologies. J. Vocat. Behav. 2004, 64, 150-164. [CrossRef]

20. Takeuchi, R.; Yun, S.; Wong, K.F.E. Social influence of a coworker: A test of the effect of employee and coworker exchange ideologies on employees' exchange qualities. Organ. Behav. Hum. Decis. Process. 2011, 115, 226-237. [CrossRef] 
21. Redman, T.; Snape, E. Exchange Ideology and Member-Union Relationships: An Evaluation of Moderation Effects. J. Appl. Psychol. 2005, 90, 765-773. [CrossRef]

22. Huseman, R.C.; Hatfield, J.D.; Miles, E.W. A New Perspective on Equity Theory: The Equity Sensitivity Construct. Acad. Manag. Rev. 1987, 12, 222-234. [CrossRef]

23. Vroom, V.H. Work and Motivation; Wiley: New York, NY, USA, 1964.

24. Abrams, D.; Hogg, M.A. Social Identity Theory: Constructive and Critical Advances; Springer: New York, NY, USA, 1990.

25. Goethals, G.R.; Darley, J.M. Social Comparison Theory: Self-Evaluation and Group Life. In Theories of Group Behavior; Springer Science and Business Media LLC: Berlin, Germany, 1987; pp. 21-47.

26. Karau, S.J.; Williams, K.D. Understanding individual motivation in groups: The Collective Effort Model. In Groups at Work: Theory and Research; Turner, M.E., Ed.; Lawrence Erlbaum Associates: Mahwah, NJ, USA, 2001; pp. 113-141.

27. Williams, K.; Harkins, S.G.; Latané, B. Identifiability as a deterrant to social loafing: Two cheering experiments. J. Pers. Soc. Psychol. 1981, 40, 303-311. [CrossRef]

28. Harkins, S.G.; Szymanski, K. Social loafing and self-evaluation with an objective standard. J. Exp. Soc. Psychol. 1988, 24, 354-365. [CrossRef]

29. Liden, R.C.; Wayne, S.J.; Jaworski, R.A.; Bennett, N. Social Loafing: A Field Investigation. J. Manag. 2004, 30, 285-304. [CrossRef]

30. Darwall, S.L. Two Kinds of Respect. Ethics 1977, 88, 36-49. [CrossRef]

31. Liden, R.C.; Maslyn, J.M. Multidimensionality of leader-member exchange: An empirical assessment through scale development. J. Manag. 1998, 24, 43-72. [CrossRef]

32. Murphy, S.M.; Wayne, S.J.; Liden, R.C.; Erdogan, B. Understanding Social Loafing: The Role of Justice Perceptions and Exchange Relationships. Hum. Relations 2003, 56, 61-84. [CrossRef]

33. Harkins, S.G.; Petty, R.E. Effects of task difficulty and task uniqueness on social loafing. J. Pers. Soc. Psychol. 1982, 43, 1214-1229. [CrossRef]

34. Chiaburu, D.S.; Baker, V.L. Extra-role behaviors challenging the status-quo. J. Manag. Psychol. 2006, 21, 620-637. [CrossRef]

35. Brislin, R.W. Translation and content analysis of oral and written materials. In Handbook of Cross-Cultural Psychology; Triandis, H.C., Berry, J.W., Eds.; Allyn and Bacon: Boston, MA, USA, 1980; Volume 2, pp. $389-444$.

36. Aiken, L.S.; West, S.G. Multiple Regression: Testing and Interpreting Interactions; Sage: Newbury Park, CA, USA, 1991.

37. Lin, C.-P. To share or not to share: Modeling knowledge sharing using exchange ideology as a moderator. Pers. Rev. 2007, 36, 457-475. [CrossRef]

38. Wheeler, L.; Reis, H.T.; Bond, M.H. Collectivism-individualism in everyday social life: The middle kingdom and the melting pot. J. Pers. Soc. Psychol. 1989, 57, 79-86. [CrossRef]

39. Earley, P.C. East Meets West Meets Mideast: Further Explorations of Collectivistic and Individualistic Work Groups. Acad. Manag. J. 1993, 36, 319-348. [CrossRef]

40. Wolfson, N.; Manes, J. The compliment as a social strategy. Pap. Linguist. 1980, 13, 391-410. [CrossRef]

41. Blanchard, K.; Lacinak, T.; Tompkins, C.; Ballard, J. Whale Done!: THE Power of Positive Relationships; Simon and Schuster: New York City, NY, USA, 2003.

42. Podsakoff, P.M.; Organ, D.W. Self-Reports in Organizational Research: Problems and Prospects. J. Manag. 1986, 12, 531-544. [CrossRef]

43. Viswesvaran, C.; Schmidt, F.L.; Ones, D.S. Is There a General Factor in Ratings of Job Performance? A Meta-Analytic Framework for Disentangling Substantive and Error Influences. J. Appl. Psychol. 2005, 90, 108-131. [CrossRef] [PubMed]

(C) 2020 by the authors. Licensee MDPI, Basel, Switzerland. This article is an open access article distributed under the terms and conditions of the Creative Commons Attribution (CC BY) license (http://creativecommons.org/licenses/by/4.0/). 